\author{
Krzysztof Lęczycki \\ Mgr inż. \\ Instytut Techniczny Wojsk Lotniczych \\ krzysztof.leczycki@itwl.pl
}

DOI: $10.35117 / A \_E N G \_18 \_09 \_04$

\title{
Selected issues of materials testing of rolling bearings adapted to work in elevated temperatures
}

\begin{abstract}
Rolling bearings are crucial component of aviation turbine engines. Bearing failure may, in worst case, lead to an engine failure and aircraft disaster. Therefore, investigation of their causes and subsequent risk factors elimination are of utmost importance. In the present study, selected materials testing issues of two rolling bearings from light rotorcraft turbine enignes failures (in accidents of 2016 \& 2017) are discussed. Results of macroscopic, hardness tests, microstructure and chemical assay are presented. The obtained data are compared with results of previous studies on the subject.
\end{abstract}

Keywords: Rolling bearings; Aviation turbine engine; Rolling bearings failure; Materials testing

\section{Introduction}

Rolling bearings are one of the critical elements of the construction of aircraft engines. Their constructional and material defects, impurities or improper operation may lead to damage to the aircraft structure during the flight, and thus to the loss of life or health of the crew. For this reason, the constructions and bearing materials of aircraft engines must demonstrate sufficient resistance to specific engine operating conditions: high shaft rotation speeds (104 rpm), vibrations, bending moments [1], high temperature.

For the construction of bearings designed for aircraft engines, high-alloy steels with an increased content of chromium, molybdenum, tungsten, vanadium resembling chemical composition and high-speed properties of tool steels are used. The presence of alloy elements forming high-melting carbides (tungsten, molybdenum, vanadium) increases the thermal stability of the material structure compared to low-alloy steels. The structure of the material after hardening and a few tempering at a temperature of approx. $550{ }^{\circ} \mathrm{C}$ is martensite with residual austenite, primary and secondary carbides. The material after the heat-improving process preserves the hardness of the steel after direct hardening due to the phenomenon of formation of alloy carbides. These types constantly retain similar hardness to approx. $500{ }^{\circ} \mathrm{C}$ after heat treatment. Steels intended for bearings for operation at elevated temperatures should contain as little residual austenite as possible after the hardening process, the minimum amount of impurities and carbides of not very large dimensions, which may be the cause of accelerated fatigue wear of the raceways of bearings [1].

In the Laboratory of Aeronautical Material Engineering ITWL (formerly Department of Materials Engineering) within 50 years many expert opinions have been made regarding damage to rolling bearings in aircraft turbine engines. A large group of 36 cases was the bearings of compressor shafts from light helicopter engines whose rolling elements and rings were made of high-alloy Cr-W-V steels for operation at elevated temperatures.

Fig. 1 presents a list of the number of bearings tested depending on the type of bearing damage, in which the following damage was distinguished: incorrect lubrication of the bearings, fatigue running off the treadmill, material defects in the form of too large carbides, cracking of bearing construction elements and others. In the last category, cases of bearing 
damage as a result of excessive action of longitudinal loads, excessive clearance in bearings and excessive loads, faulty bearing performance, electric arcs between the outer ring and the injector were presented [5]. The most common causes of bearing damage were fatigue running off the treadmill (47\%) and incorrect lubrication of the bearings $(25 \%)$.

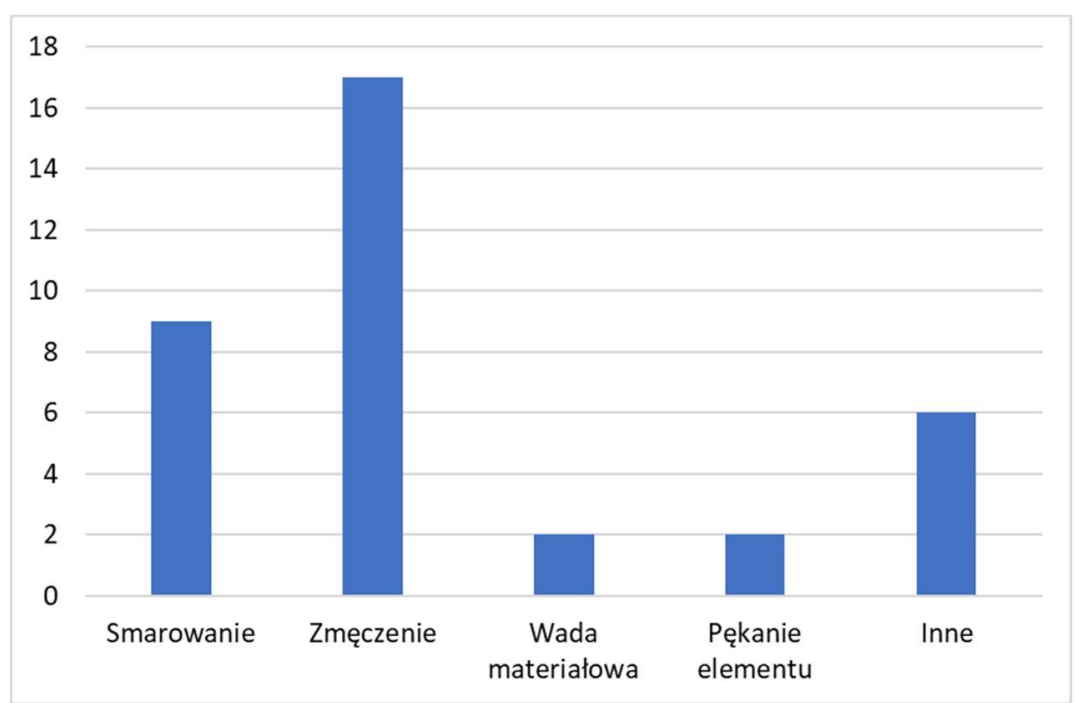

1. List of causes of damage to rolling bearings of a light helicopter compressor turbine, (based on the archive of the Institute of Aviation Material Engineering, ITWL)

The last cases of bearings failure in this type of engine were investigated in the Aeronautical Clients' Laboratory in 2016 and 2017. Both failures occurred as a result of incorrect lubrication of bearings. The aim of this study is to present the microstructure and mechanical properties of damaged bearing materials and compare them with two cases tested in previous years.

\section{Material testing of rolling bearings}

\section{Cases from 2016 and 2017}

In 2016 and 2017, two similar cases of spontaneous switching off of one of two light helicopter engines during start-up [3], 4] were reported. In both cases, turbine compressors were blocked due to damage to the bearing of the same motor support. The bearing tested in 2016 for the purpose of this study was determined as bearing A, the bearing tested in 2017 was determined as bearing $\mathrm{B}$. The rings and ball bearings were made of chrome-tungstenvanadium steel, while the separator was made of aluminum-iron-nickel bronze. carried out:

In the Laboratory of Aeronautical Material Science ITWL, the following tests were

- macroscopic observations with the unaided eye and using the Nikon SMZ 800 stereomicroscope,

- $\quad$ structure studies using the Nikon Eclipse MA200 metallographic microscope,

- $\quad$ chemical composition studies using the LINK XIS microanalyzer ISIS L200 coupled with the JEOL JSM 5400 scanning electron microscope,

- Vickers hardness measurements with the use of the DuraScan 20 hardness tester. A Laboratory of Aeronautical Materials Testing accredited at the Polish Center for Accreditation under the number $\mathrm{AB}$ - 431. The following loads were applied: $0.5 \mathrm{kG}$, $1 \mathrm{kG}, 10 \mathrm{kG}$.

\section{Macroscopic examination}


Both objects tested were single row deep groove ball bearings with a divided internal race. Their damage consisted of breaking the separators into two parts (cracking occurred in the thinnest places of the balls' nests) and their significant plastic deformation with the traces of tearing the balls onto the sockets. The treadmills and balls were covered with a layer of foreign material, the non-working surfaces were oxidized. An example of a delivered bearing (bearing B) for tests is shown in Fig. 2. The bearing B is supplied together with the damping sleeve applied to it, while in the case of the bearing A the damping sleeve is not provided.
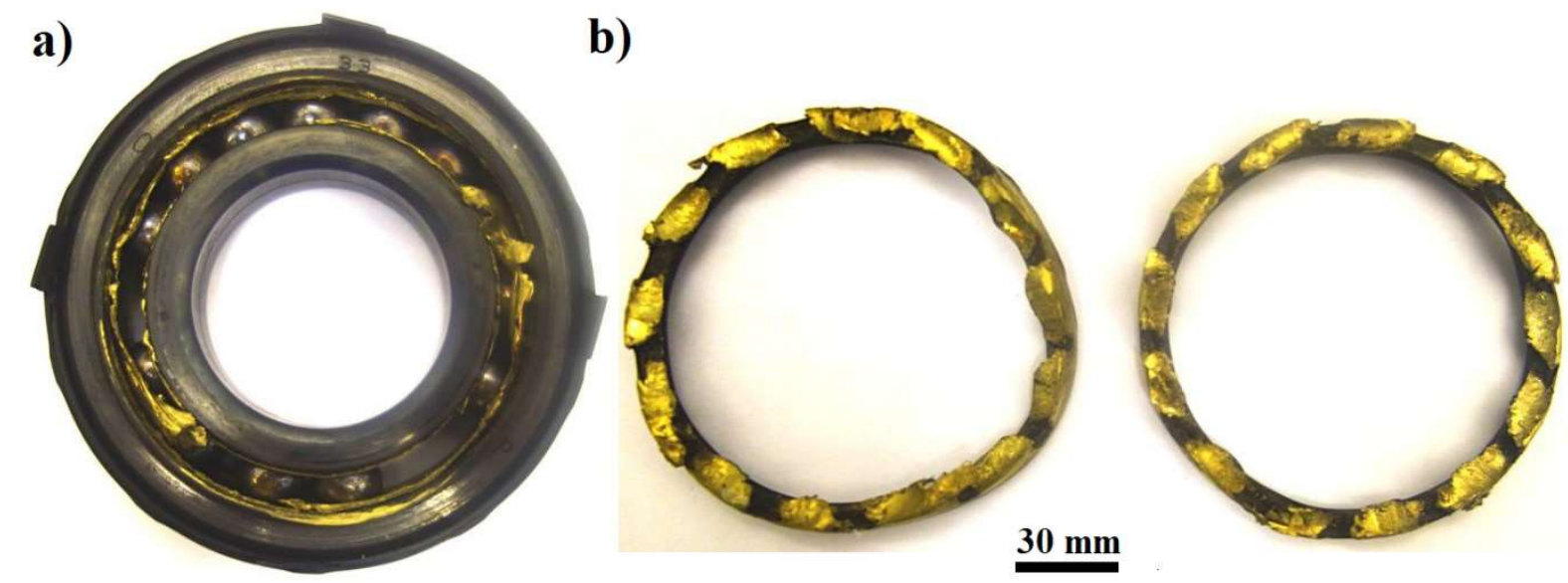

2. Bearing B in test delivery condition:

a) outer ring, internal half-washers, balls, silencer; b) separator

Despite the quite similar type of damage, both bearings show clear differences. The bearing $\mathrm{B}$ was rotated in relation to the damping sleeve after locking, as evidenced by the circumferential cracks on the external surface of the outer ring (Fig. 3a) and peripheral cracks and thermal discolorations on the inner surface of the damping sleeve (Fig. 3b). Such traces were not found in bearing A.
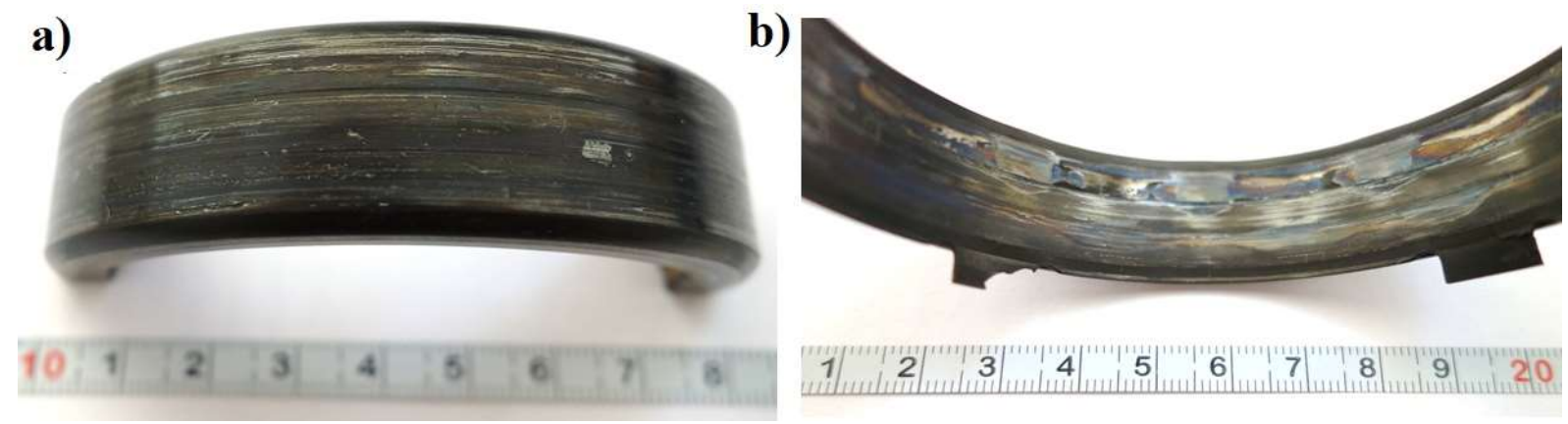

3. a) Outer surface of the outer bearing ring B;

b) the inner surface of the vibration damping sleeve

Another difference is the appearance of the foreign material layer, which was applied to external treadmills (Fig. 4) and internal treadmills (Fig. 5). In the case of bearing A (Fig. $4 \mathrm{a}, 5 \mathrm{a})$, the foreign material layer has a dark yellow hue, is rough and contains discontinuities revealing the tread surfaces locally. In addition, on the outer treadmill (Figure 4a), the protrusions on the foreign material layer are distributed at regular intervals corresponding to the arrangement of the balls. The layer of foreign material applied to the bearing track B (Fig. $4 \mathrm{~b}, 5 \mathrm{~b})$ is smoother, with no discontinuities, has a non-uniform color: in places, it is dark yellow, sometimes dark gray. The inner half-washers were connected through it (Fig. 5b). At the tread edge, it creates larger flashings compared to those observed in bearing A. 

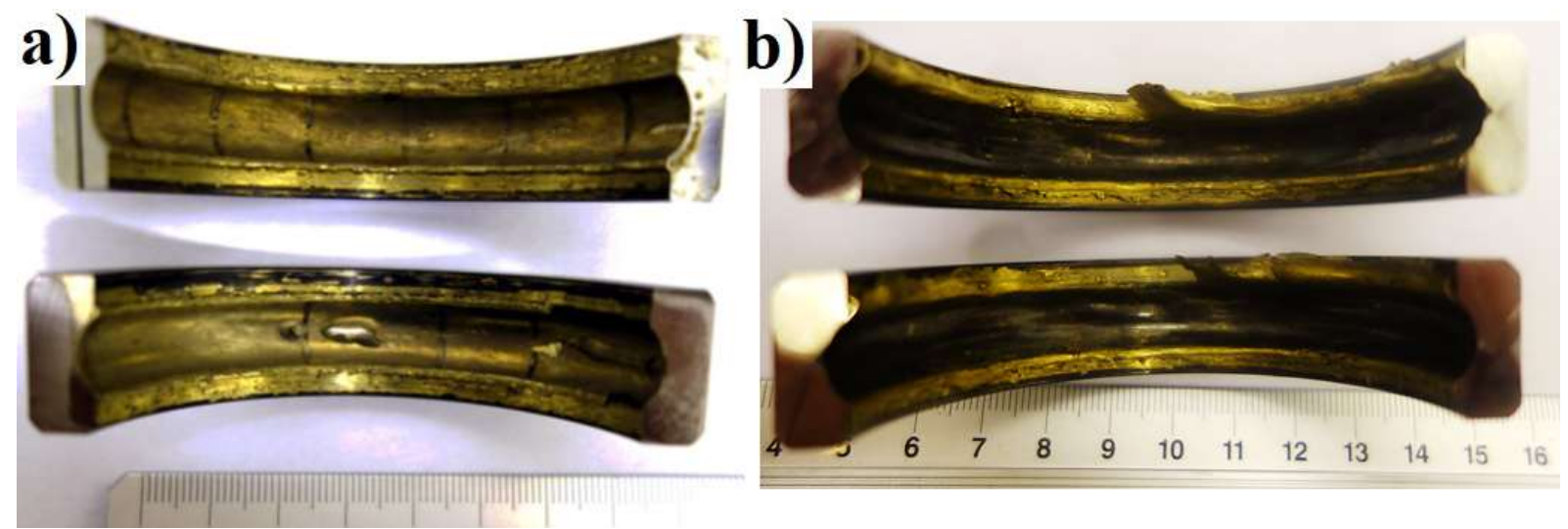

4. Outer rings after cutting: a) bearings $A$; b) bearings $B$

a)

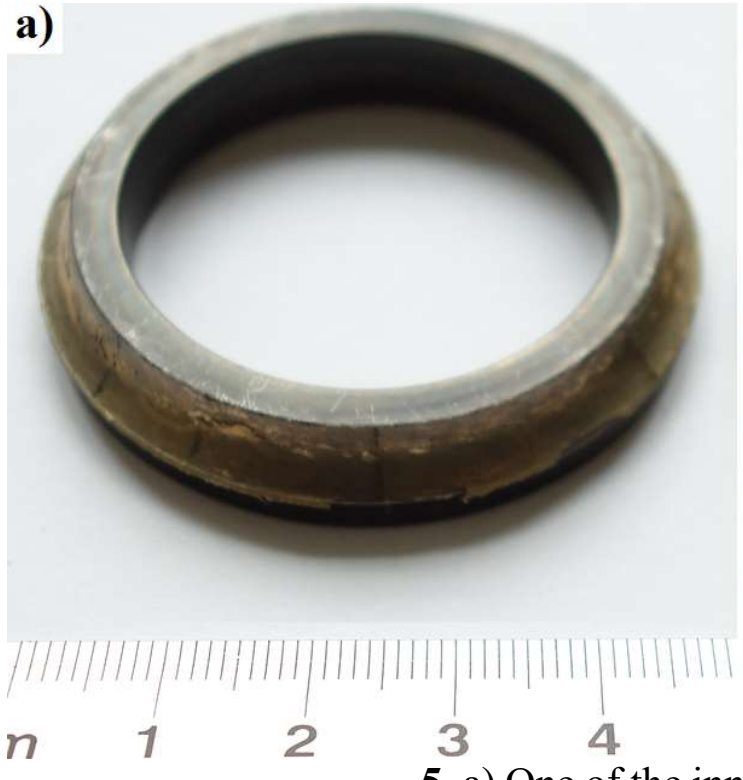

5. a) One of the inner rings of the bearing A;

b) the inner half-rings of the bearing $\mathrm{B}$ connected b)

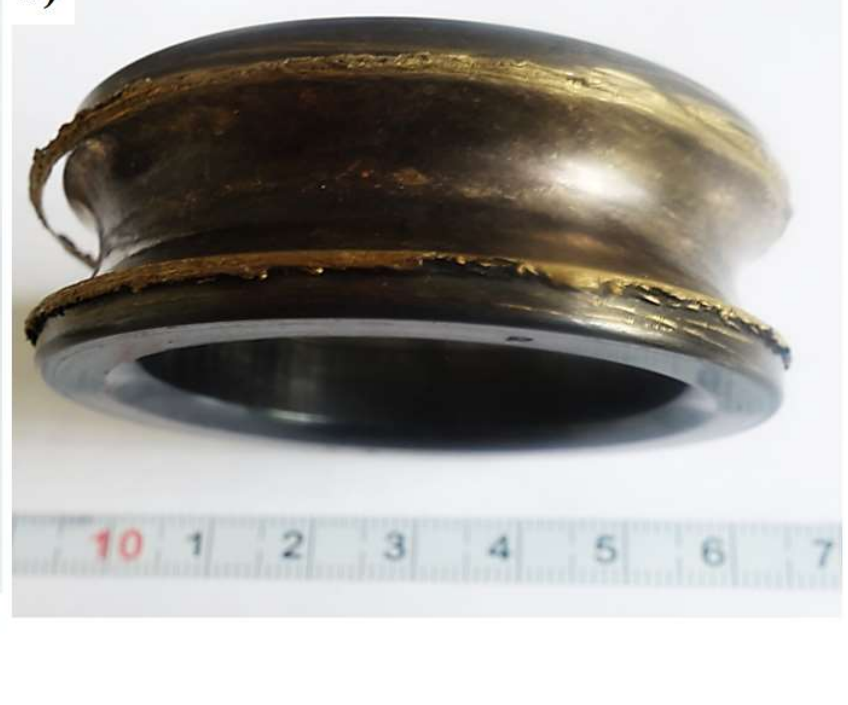
ed

The layer of foreign material was also applied to the surfaces of outer rings adjacent to the outer centering surfaces of the separators (Figure 4). In both cases, its appearance is similar: it has a pale yellow color with visible flattened lumps of the same color. This shows together with the circumferential features on the outer surfaces centering the rubbing of the separators when the bearing is in operation with the outer rings (fig. 6). Fragments of the bearing separator B are assessed as more deformed than the bearing A due to the more pronounced bending of the separator rings and the flattening of damaged balls' nests.

The balls of both bearings (Fig. 7) have a different surface appearance - the balls from bearing $\mathrm{A}$ are covered with a dark-yellow foreign material similar to that observed in the treadmill, longitudinal beads of foreign material are visible after breaking the balls from the treadmill, cracks are visible ( Fig. 7b), while in the case of balls from bearing B the surface is dark with numerous traces of abrasions (Fig. 7d). 


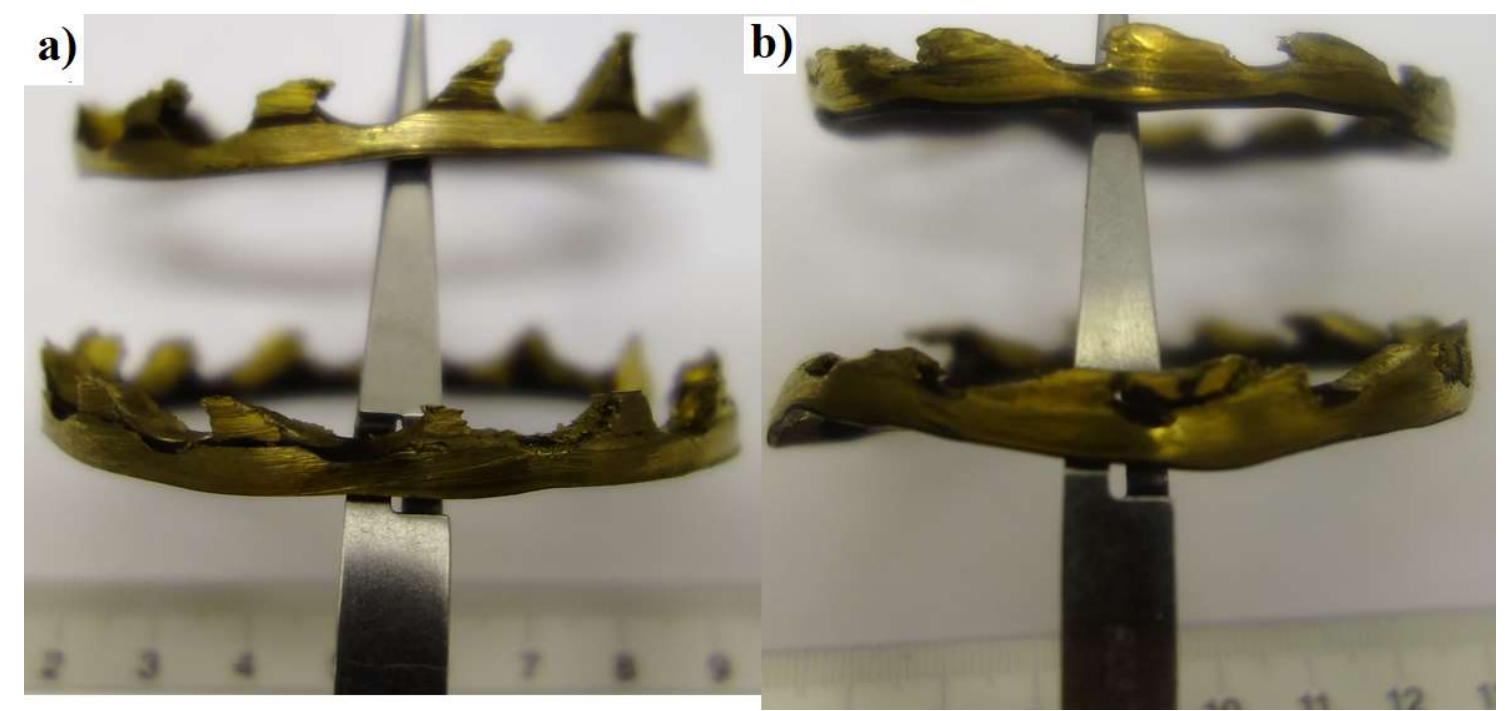

6. The outer centering surface of the separator: a) bearings A; b) bearings B
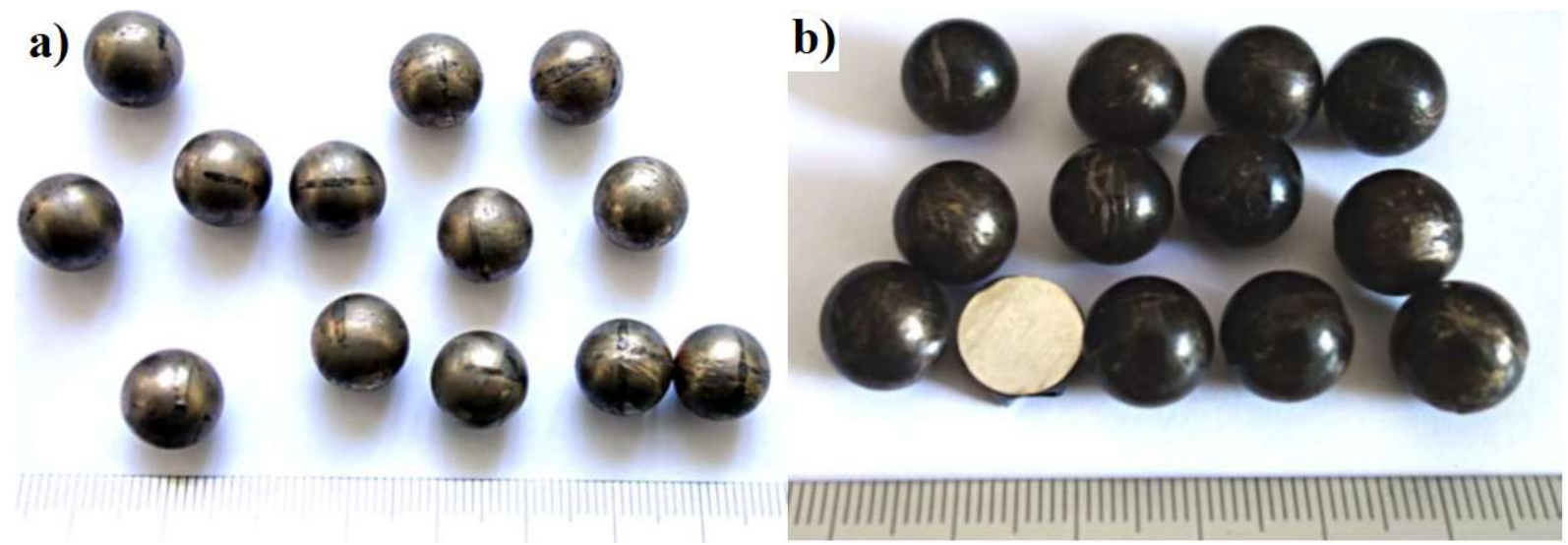

7. a) Bearing balls $A$; b) the surface of one of the bearing beads $A$;

c) Bearing balls (one of the balls has been cut)

\section{Studies of structure, hardness and chemical composition}

Metallographic cuts were made of samples taken from cross-sections of outer rings, internal half-rings, and balls. All the treatments were cut with a $2 \%$ solution of nitric acid in ethyl alcohol (nital). After metallographic studies, the grinds were subjected to hardness tests.

On macroscopic photographs of the cutouts of the cross-sections of the outer rings of both bearings (Figure 8), thermal degradation zones (SDC) are visible which manifest themselves in a different method of grinding and a layer of foreign material. In the case of the outer ring of the bearing A (Fig. 8a), the SDC is observed in the entire region of the treadmill and at the edges adjacent to the separator. The sample of the outer bearing ring $\mathrm{B}$ shows a greater number of SDCs: on one of the faces and on the outer surface, which is related to the rotation of the outer ring relative to the damping sleeve. It should be noted that the observed SDC, especially in the area of the raceway, are not symmetrical, especially in the case of the outer ring of the bearing B. This may be related to the place of application of the maximum radial forces. 


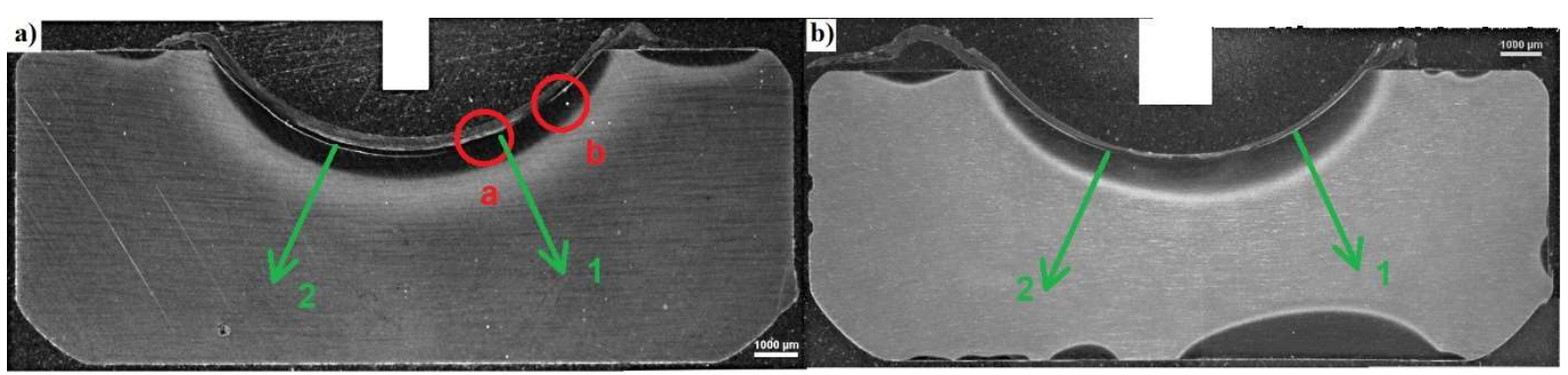

8. Macroscopic photo of a nital-cut grinding of a metallographic cross-section of an outer ring with marking of further observation points and hardness measurements:

a) bearings $\mathrm{A}$; b) bearings $\mathrm{B}$

The correct microstructure of the steel parts of the bearing is shown on the example of the outer ring of the bearing A (Fig. 9a), which is tempered martensite with carbides. The measured hardness is $789 \pm 11 \mathrm{HV} 10$, while the required hardness is 694-809 HV10. The microstructure in the surface area of the thermal degradation zone is shown in Fig. 9b, it is undissolved martensite with carbide precipitates. Such a structure is created by heating the steel to the austenitizing temperature $\left(900-1000{ }^{\circ} \mathrm{C}\right.$ in the case of $\mathrm{Cr}-\mathrm{W}-\mathrm{V}$ alloy steels) and sufficiently fast cooling. The example hardness measured in such a zone is 769 HV1 (Fig. 9b).

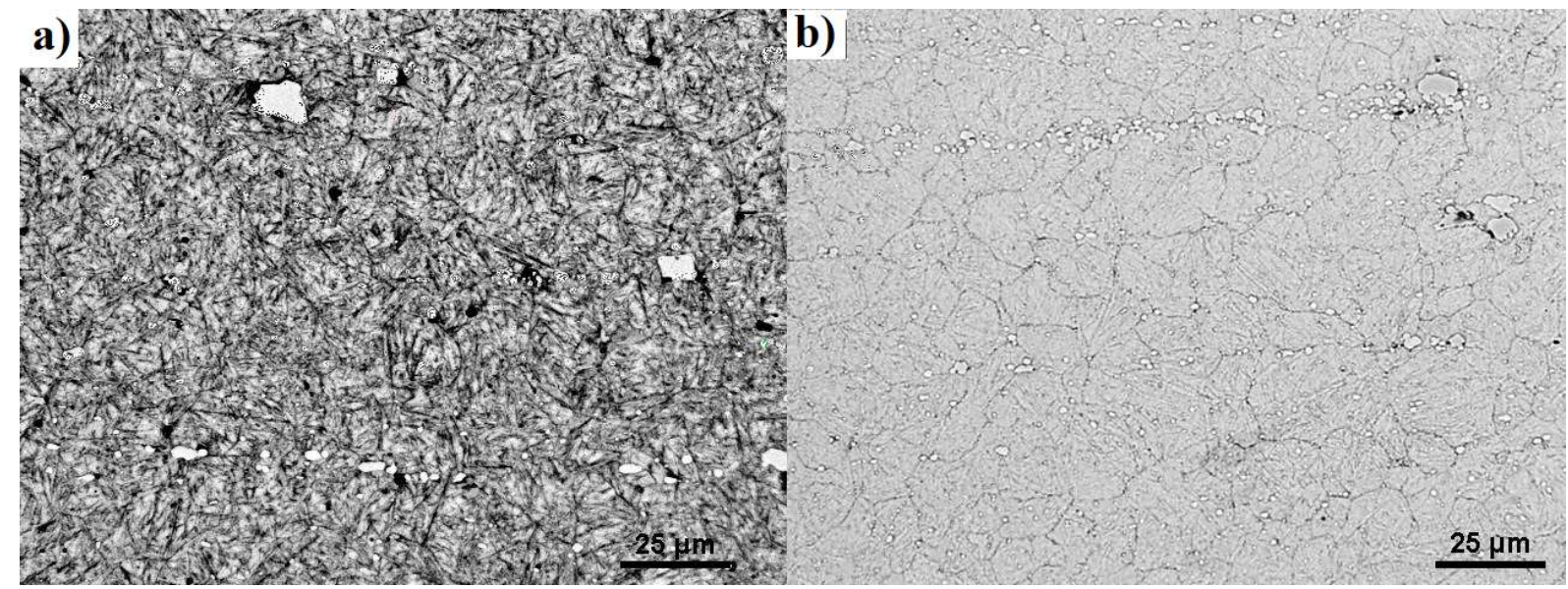

9. a) Microstructure of the core of the outer ring sample - normal microstructure, hardness 789 HV10, b) microstructure at the surface of the thermal degradation site - microstructure after secondary hardening, hardness $769 \mathrm{HV} 1$

The SDC depth was estimated using linear hardness distributions (Fig. 10), behind which the distance from the cross-sectional edge was taken to the place where the material reached the hardness in the core. The measured hardnesses at the cross-sectional edge in the SDC usually have a hardness close to or greater than the hardness of the material in the core, which as mentioned above is related to the subsequent quenching of the material. The gradual lowering of the temperature causes the tempering process to take place, i.e. the formation and growth of carbides. The minimum drop in hardness is observed at $700-800{ }^{\circ} \mathrm{C}$.

On the basis of the obtained results, it can be stated that the SDC depth measured in the outer ring of the bearing at similar measuring points is significantly higher compared to bearing $\mathrm{A}$. in the place of series 1 the material does not achieve core hardness due to the proximity of another SDC (Fig. 8b). In place of series 2 about twice as large SDCs were obtained. The hardness measured in the core of the outer bearing B ring (718 \pm 16 HV10) is smaller compared to bearing A (789 HV10) due to the larger thermal-degraded area. 


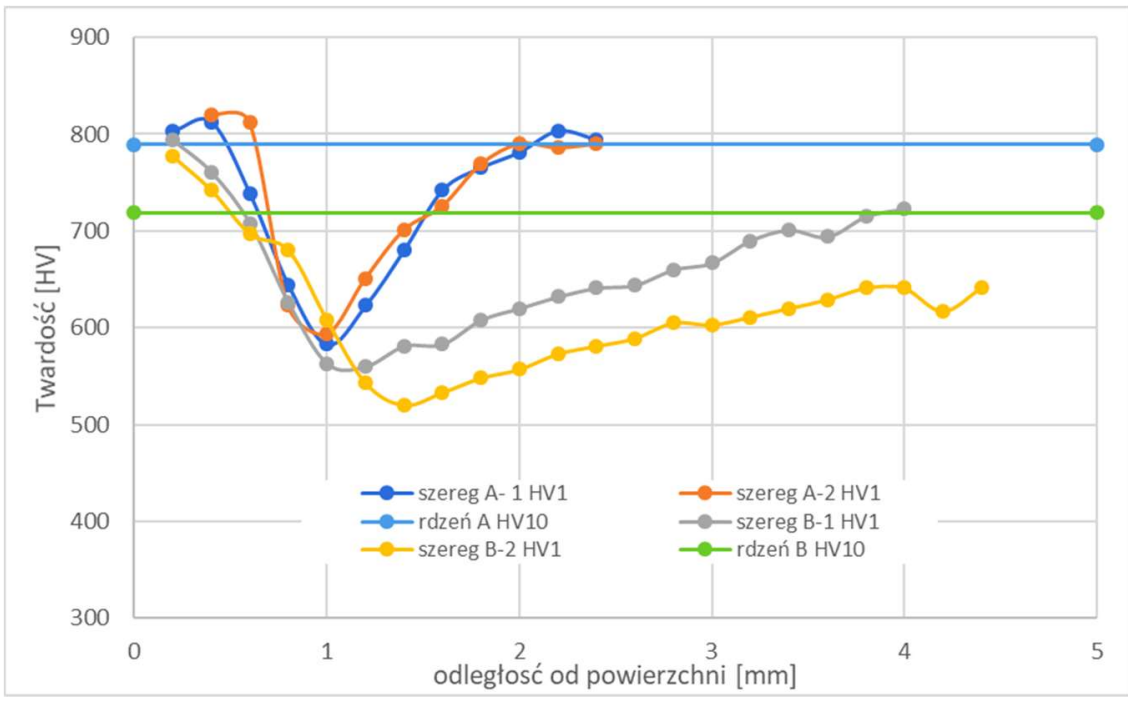

10. Diagram of dependence of hardness on the distance from the surface of the outer ring of bearings $\mathrm{A}$ and $\mathrm{B}$, taking into account the hardness measured in the core of the samples

Fig. 11 shows the microstructure of the foreign material layer applied to the external race of bearing $\mathrm{A}$ in four places as indicated in Fig. 8a. This layer differs in construction depending on the place of occurrence. In place of the largest balls pressure on the outer treadmill (Figure 11a), the foreign material layer adheres closely to the ground. It is composed of two sublayers - chemical composition tests have shown that the lower sublayer consists of chemical elements of the bearing steel (iron, chromium, tungsten, vanadium), while the upper sublayer consists of a mixture of elements both in the chemical composition of the bearing steel and separator material (copper, aluminum, nickel, iron, chrome, tungsten, vanadium). The boundary between the sub-layers is hardly visible. In the area of "b", the separation boundary is more visible, the upper sublayer contains pores and thin inclusions with a bright shade. Delamination is also characteristic. Both sublayers coexist along the entire periphery of the treadmill. The thickness of the layer is between 213-342 $\mu \mathrm{m}$. The layer has a minimum thickness in the area of close adhesion (no delamination).

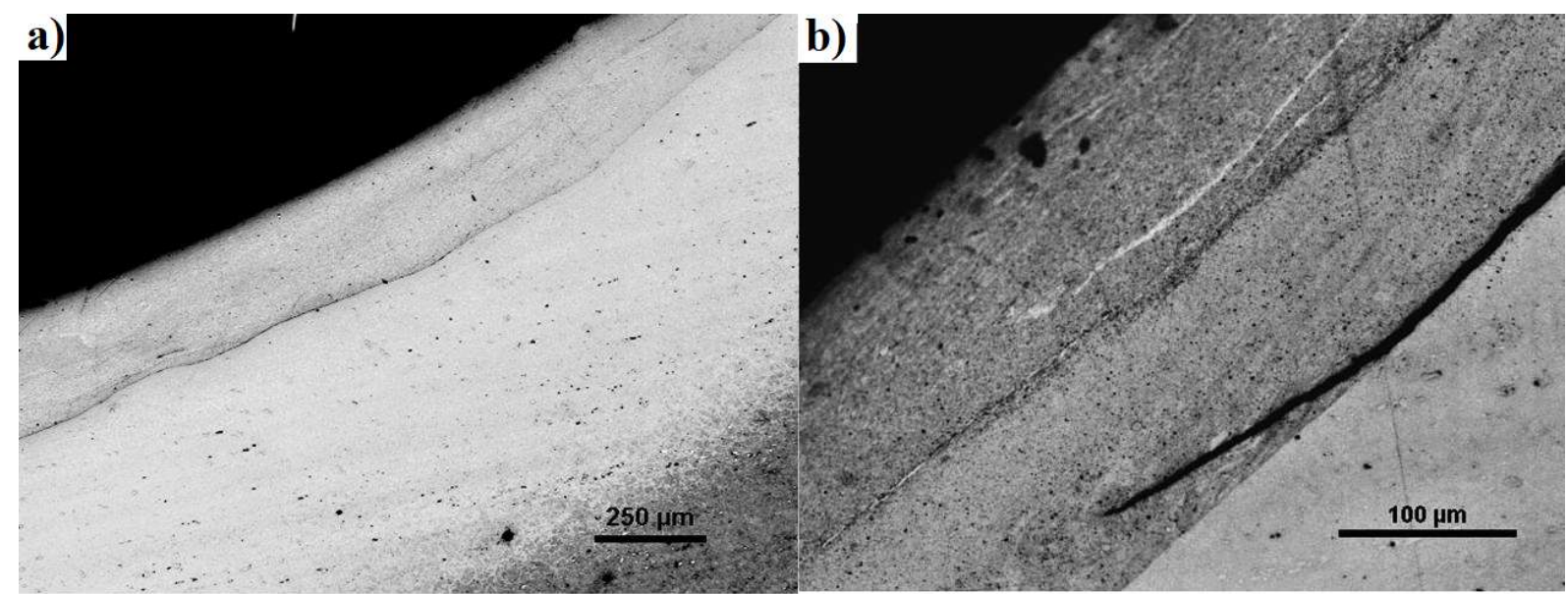

11. The microstructure of the areas at the bearing outer race $A$ on the basis of Fig. 10a: a) the center of the treadmill; b) the rest of the treadmill

The layer of foreign material applied to the outer race of bearing B (fig. 12) is significantly different to bearing A. Two sub-layers can also be distinguished, but they coexist only in the area adjacent to the beginning of delamination. In the middle of the treadmill, the 
layer consists of abraded steel bearing elements (measured hardness is $809 \pm 18 \mathrm{HV} 0,5$ ) again hardened and hardened. Towards the edge of the treadmill, a foreign material layer consisting of a mixture of materials begins to appear (the measured hardness is $290 \pm 15 \mathrm{HV} 0,5$ ). The thickness of the foreign material is in the range of 105-196 $\mu \mathrm{m}$, which is much less compared to the bearing A. The layer with the largest thickness is located in the central part of the treadmill.

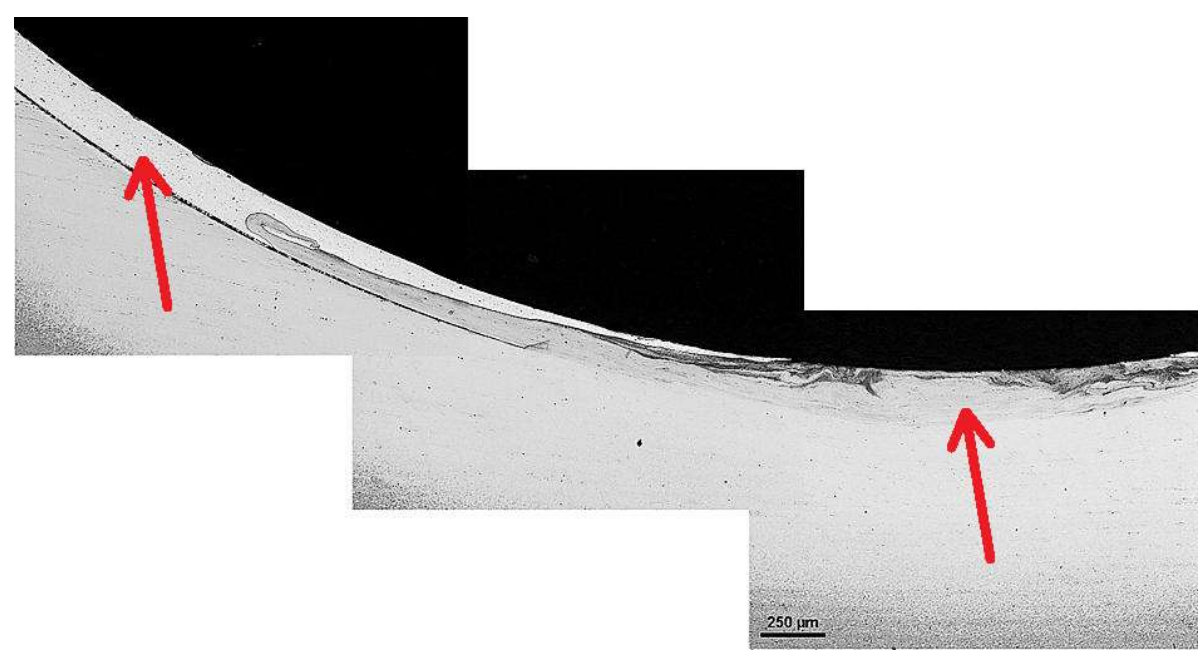

12. Microstructure of the central part of the outer race of bearing $B$, with indication of the place of measurement of the hardness of the layer

The etching of the half-rings of the internal ring samples in both cases revealed the SDC. Another feature common to the damage of the half-rings is the presence of a flash at the edge of the treadmill, which is the effect of the plastic deformation of the treadmill. A layer of foreign material, most likely a mixture of steel and bronze from the separator, is also visible on the flash. The material microstructures in the SDC are similar to those shown in Figure 9b. In the case of the half-washers of the B bearing, there was a permanent connection at the edge of the treadmill, which cracked while cutting the half-rings.

The SDC depth in the internal half-washers was also estimated based on linear hardness distributions (Fig. 14). The places of their execution are shown in Fig. 13. The "1" measurement series were made throughout the cross-section of the samples, which proves overheating of both half-rings, however, in the case of bearing A, the hardness curve tends to be measured in the core $(770 \pm 7 \mathrm{HV} 10)$, while the dependence for bearing $\mathrm{B}$ is approximately decreasing over the entire measuring section (material hardness in the core: $742 \pm 20$ HV10). In the measuring series "2" of bearing B, the material has also overheated through, in the case of the bearing the depth SDC is approx. $2.7 \mathrm{~mm}$.

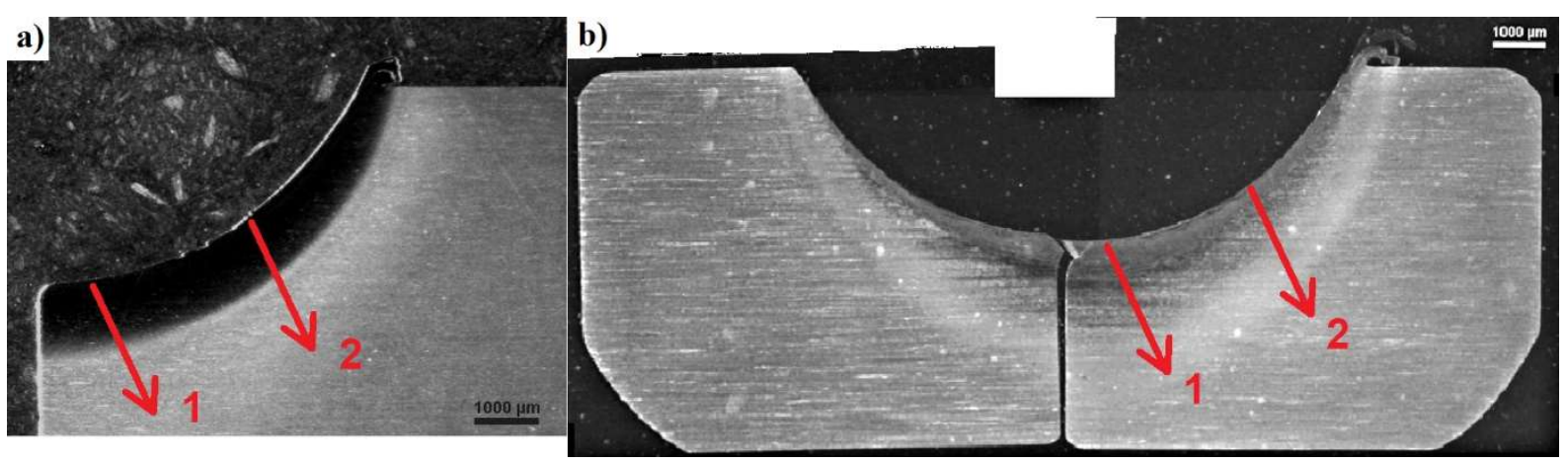

13. Macroscopic photo of the nital-cut:

a) Half-washer of the inner bearing $\mathrm{A}$; b) both half-rings of bearing $\mathrm{B}$ 


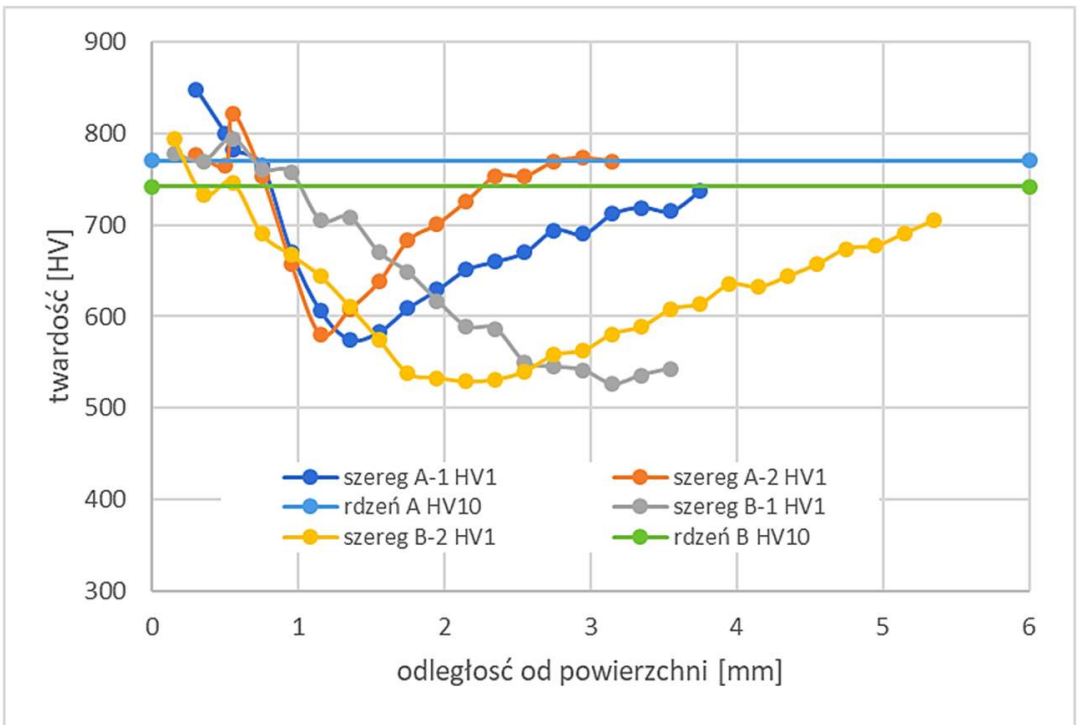

14. Diagram of the hardness dependence on the distance from the surface of the inner and outer rings of the bearings $\mathrm{A}$ and $\mathrm{B}$,

taking into account the hardness measured in the cores of the samples

The microstructures of the ball cores of bearings $\mathrm{A}$ and $\mathrm{B}$ correspond to the microstructure shown in Fig. 9b, while the microstructures of the subsurface zones are shown in Fig. 15. In both cases, the hardening of the balls was found throughout. At the edges of the cross-sections, you can see the wipes and the material that has been attached to the surface of the beads.
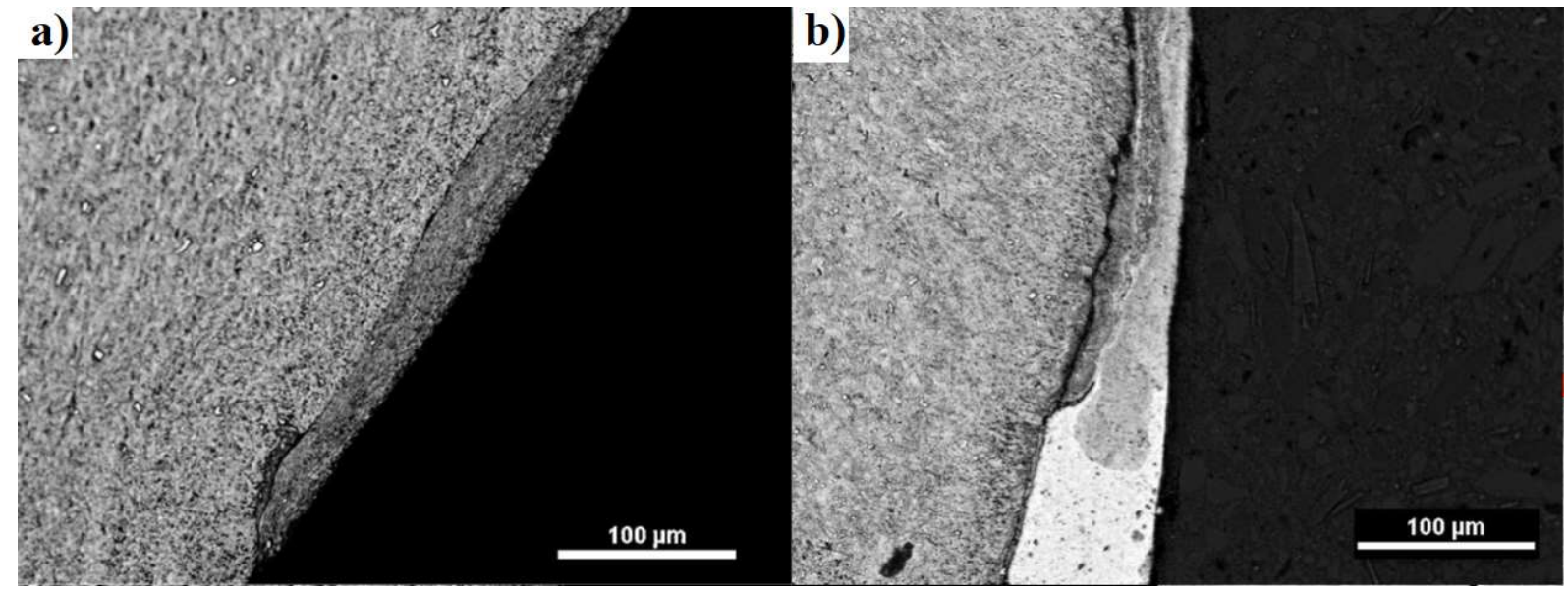

15. Microstructure of the ball cross-section (nital etching) at the cross-section edge:

a) bearings $\mathrm{A}$ b) bearings $\mathrm{B}$

\section{Mechanism of damage}

On the basis of the material test results quoted above, the following mechanism of destruction of both bearings can be presented at the time of stopping the inflow of oil:

- abrasion of bearing steel elements, rolling of filings into cooperating elements, increase of resistance to movement and increase of the bearing temperature to the austenitizing temperature $\left(900-1000^{\circ} \mathrm{C}\right)$;

- pushing the balls onto the separator sockets susceptible to deformation at high temperature, abrasion of sockets, mixing of bronze filings with steel filings; 
- in case of bearing B, after destruction of the separator, the bearing was blocked and rotated in the damping sleeve.

Bearing $\mathrm{B}$ is considered more damaged due to the larger surface area of the SDC, especially in the outer ring, the combination of both inner half-rings and more deformed parts of the separator.

\section{Previous research}

The bearing case from a light helicopter engine, in which the separator was also broken, and the cause of the failure was inadequate bearing lubrication was found in 1984 [6]. However, the separator, in contrast to the previously discussed cases, was torn apart into more pieces, the largest of which is shown in Fig. 16. The balls were largely abraded, the inner half-rings were distorted, and the foreign material from the grated filings was applied to the friction pairs.

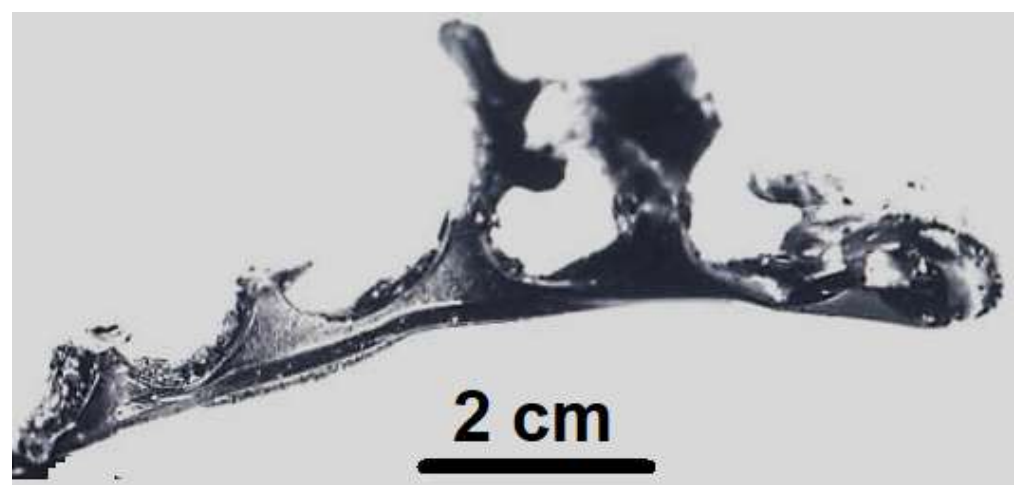

16. Elements of the damaged bearing tested in 1984. with the selection of metallographic sampling sites [6]

Observations of the inner-ring grinders (Fig. 17) revealed the presence of SDC (nondefective areas), much larger than the cases from 2016 and 2017. The SDC in one half-ring almost the entire sample, the half-ring is clearly distorted and has a flash at the edge of the treadmill. Observations of the microstructure of the half-ring in the area "I" (Fig. 18a) and beads (Fig. 18b) revealed the presence of microcracks. The microstructure of the outer treadmill resembled the one shown in Fig. 11a. The hardness of materials and their microstructure made in undamaged places met the technical requirements.

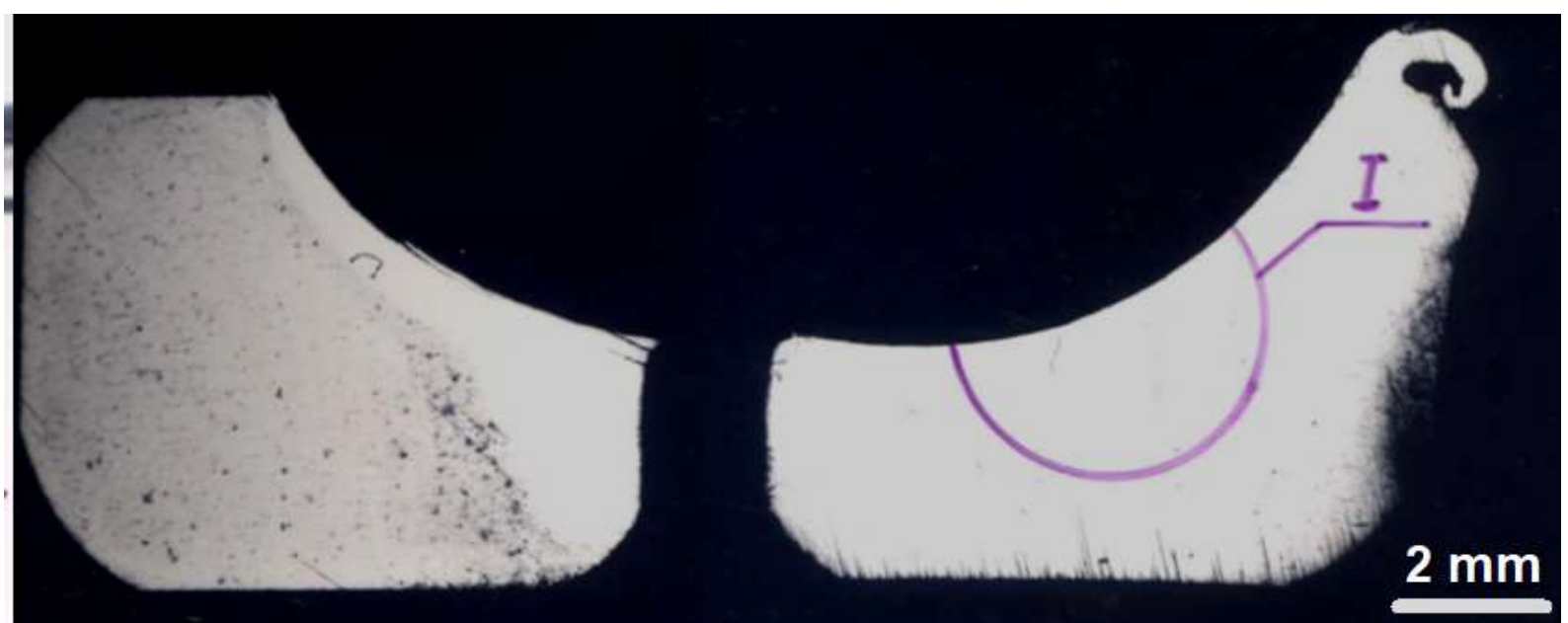

17. Spacing of cross-sections of samples of inner-ring nibs etched with nital, marking the place of observation under greater magnification [6] 


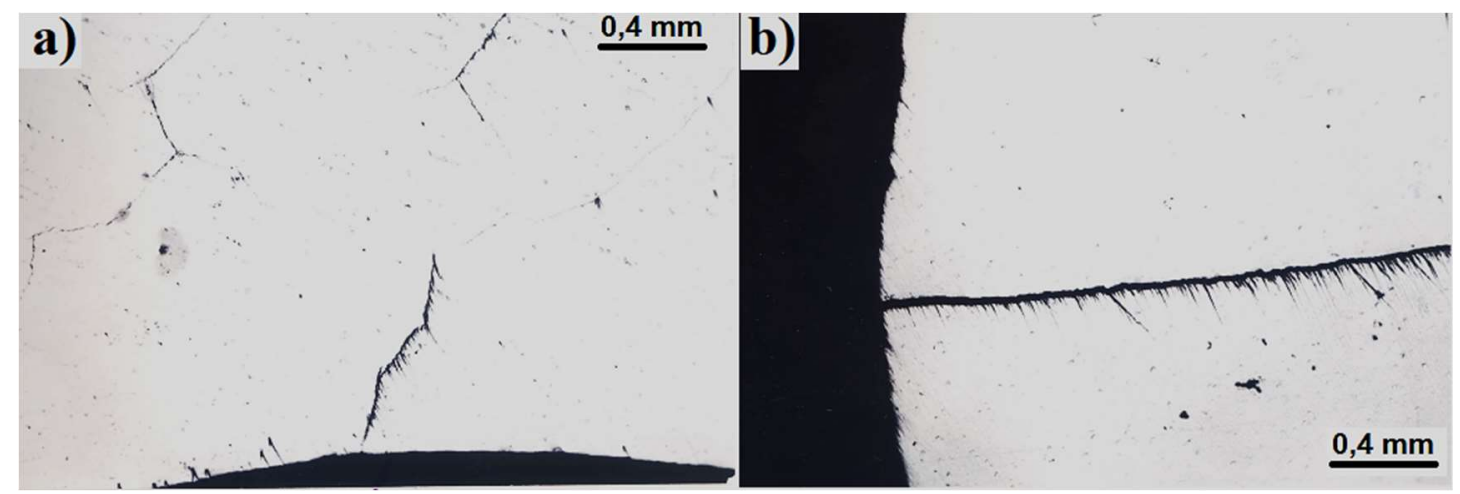

18. a) The microstructure of the section cut in the area marked in Fig. 17;

b) The microstructure of the cross-section of the ball [6]

Significant distortion of the half-rings, balls, destruction of the separator and the presence of microcracks inside the ring and the ball indicate the destruction of the bearing at high temperature and with a significant increase in loads.

In the history of investigations of this type of bearings carried out at the ITWL, there have been cases of failure, the feature of which was the failure of the separator without its fragmentation. This type of event was examined in 1979 [2]. The damage consisted of significant deformation and ball clumping, application of the ball material to the outer race track and burning of the oil on it (Fig. 19a), plastic deformation of the internal half-rings (Fig. $19 \mathrm{~b})$ and their cracking. The separator wore traces of abrasion on the inner centering surface.

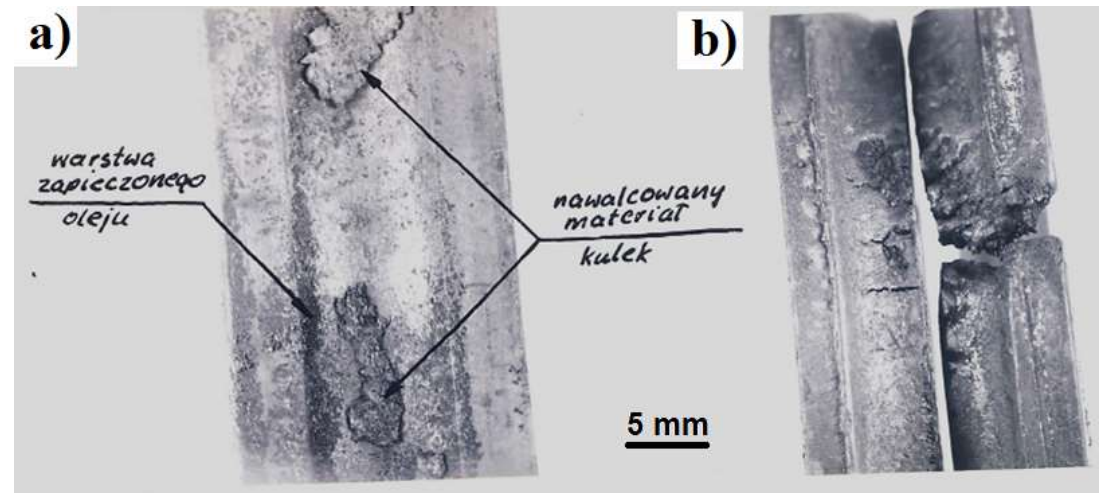

19. a) The surface of the outer race, b) The surface of the inner race [2]

Fig. 20 shows the macroscopic images of section cuts of steel parts of the bearing. The edges were cut with nital. The outer ring has a relatively small thermal degradation zone (much higher in cases of 2016 and 2017) with a layer of ball material deposited in the middle of the treadmill. The beads and half-rings were resistant to the etching factor, which indicates overheating of these elements throughout. In addition, on one of the half-rings, there is a material flash at the edge of the tread near the above-mentioned cases. The studies on the microstructure and hardness of the outer ring outside the SDC do not raise any objections. In the case of internal half-rings and balls, the structure of undesired martensite was found, thus re-hardening the materials. The trace of seized oil on the outer treadmill indicates an insufficient supply of oil to the Bering. 


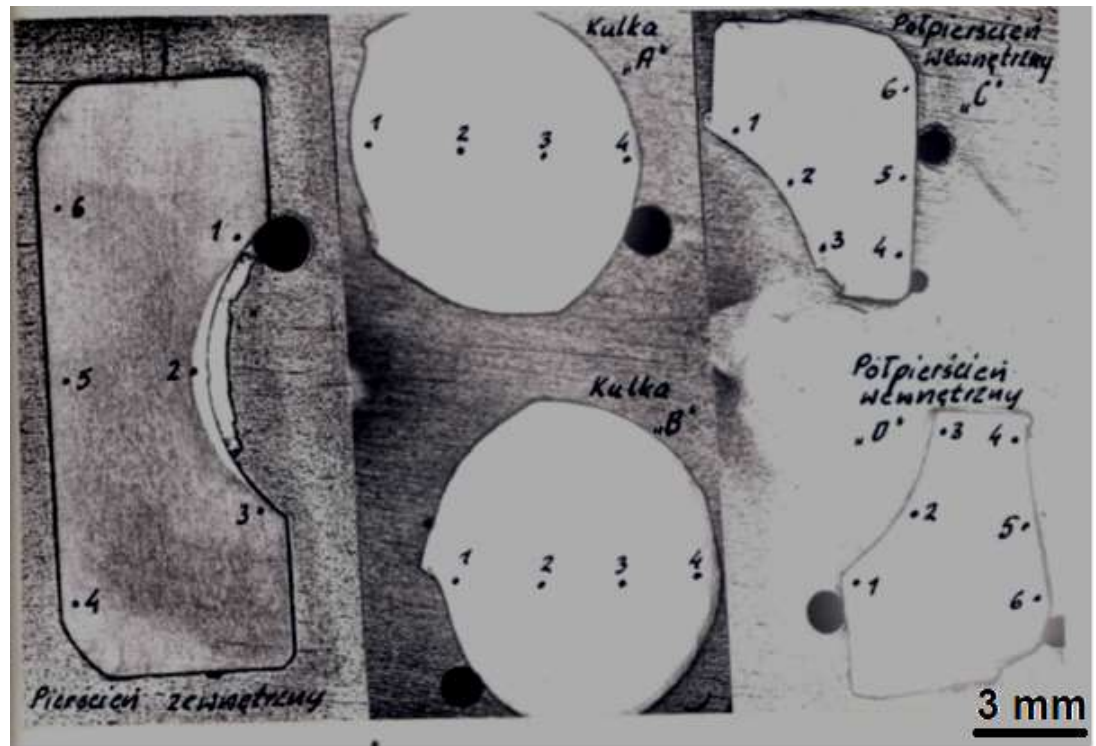

20. Macroscopic images of nital-etched cross-cuts of the outer ring, balls and internal half-rings with marking of hardness measurement points [2]

\section{Summary}

Lack of oil supply to the bearing or supplying it in the wrong amount causes damage to the bearing in a way dependent on the temperatures encountered, mechanical loads and the duration of unfavorable conditions. The discussed cases of bearing failures differed in the degree of abrasion of the elements cooperating with each other, the way the separator was damaged, the structure and the chemical composition of foreign material layers applied to the elements cooperating with each other, structures and properties of materials. Common features of the discussed cases were overheating of the rolling elements (re-hardening), overheating through at least part of the material of the inner ring, plastic deformation of the edges of one inner ring in the treadmill area, application of foreign material to the race of the outer ring.

\section{Source materials}

[1] Bhadeshia H. K. D. H., Steels for bearings, Progress in Materials Science 57, 2012268 435.

[2] Bonicki A., Opracowanie ITWL - materiały niepublikowane, 1979.

[3] Dudziński A., K. Łęczycki, Opracowanie ITWL - materiały niepublikowane, 2016.

[4] Dudziński A., K. Łęczycki, Opracowanie ITWL - materiały niepublikowane, 2017.

[5] Lisiecki J., Opracowanie ITWL - materiały niepublikowane, 1995.

[6] Tomaszewski H., Opracowanie ITWL - materiały niepublikowane, 1984. 